САВЧЕНКО Ирина Александровна - доктор социологических наук, профессор кафедры философии, социологии и теории социальной коммуникации Нижегородского государственного лингвистического университета им. Н.А. Добролюбова (603155, Россия, г. Нижний Новгород, ул. Минина, 31a); профессор кафедры психологии и педагогики Нижегородской академии МВД РФ (603144, Россия, г. Нижний Новгород, Анкудиновское ш., 3; tеоsтасо@rambler.ru)

СНЕГИРЕВА Людмила Анатольевна - кандидат психологических наук, доцент; начальник кафедры психологии и педагогики Нижегородской академии МВД России (603144, Россия, г. Нижний Новгород, Анкудиновское ш., 3; sla_sq@таil.ru)

УСТИНКИН Сергей Васильевич - доктор исторических наук, профессор; декан факультета международных отношений, экономики и управления, профессор кафедры международных отношений и политологии Нижегородского государственного лингвистического университета им. Н.А. Добролюбова (603155, Россия, г. Нижний Новгород, ул. Минина, 31а); директор Приволжского филиала Федерального научно-исследовательского социологического центра РАН (603000, Россия, г. Нижний Новгород, пер. Холодный, 4; sv.ustinkin@gmail.com)

\title{
МЕЖДУ СУРОВОСТЬЮ И НЕОТВРАТИМОСТЬЮ: ПРОТИВОДЕЙСТВИЕ КОРРУПЦИИ В ПОНИМАНИИ РАЗЛИЧНЫХ ГРУПП НАСЕЛЕНИЯ
}

\begin{abstract}
Аннотация. В настоящее время как ученых, так и людей, далеких от науки, волнуют примерно одинаковые вопросы, связанные с противодействием коррупции. В каком случае борьба с коррупцией будет эффективнее: при максимально суровом наказании или в случае неотвратимости наказания, при котором его жесткость имеет второстепенное значение? Возможно ли в принципе победить коррупцию? Для того чтобы получить ответы на данные вопросы от представителей различных групп населения, авторы проводят опросное исследование среди офицеров полиции, курсантов вузов МВД, представителей гражданских профессий и студентов гражданских вузов.

Ключевые слова: противодействие коррупции, взяточничество, суровость наказания, неотвратимость, офицеры полиции, органы внутренних дел
\end{abstract}

Введение. Коррупция - один из больших вызовов как для России, так и для всего мирового сообщества. Не случайно построение общества без коррупции объективно является приоритетным ориентиром социального развития во многих странах [Davis, Ruhe 2003; Wilhelm 2002; Nielsen 2003].

Между тем коррупция - комплексная проблема, включающая в себя юридические, социологические, экономические, этико-философские и многие другие аспекты [Савченко 2019]. Несмотря на появление весьма интересных исследований, направленных на теоретическое обоснование вопросов, связанных с противодействием коррупции [Баумик 2015; Добросоцкий 2016; Gokcekus, Bengyak 2014], междисциплинарные и кросс-методологические особенности обсуждаемой проблемы [Савченко, Снегирева, Устинкин 2018] затрудняют формирование концептуального монофундамента антикоррупционной деятельности.

Постановка проблемы. Для ученых до конца не ясно, в каком случае борьба с коррупцией будет эффективной. При жестком контроле и ужесточении наказания за коррупционные деяния? Или, возможно, при обеспечении неотвратимости наказания? И в этом случае, по всей вероятности, жесткость наказания имеет второстепенное значение? Можно ли вообще победить коррупцию? Подобные вопросы объективно возникают не только перед учеными, но и 
перед представителями различных групп общественности. Данные соображения побудили авторов статьи провести опросное исследование.

Цель исследования. Цель опросного исследования, о котором идет речь в настоящей статье, - установить отношение разных групп населения к концептуальным установкам, на которых могла бы формироваться система противодействия коррупции. Авторы стремились в первую очередь выяснить мнение респондентов по поводу наиболее эффективного метода противодействия коррупции - суровости наказания или же его неотвратимости.

Характеристика выборки. Целевая выборка, которая была задействована и в других опросных исследованиях авторов статьи [Савченко, Снегирева, Устинкин 2019а; 2019б], была сегментирована следующим образом: 1) действующие офицеры полиции (164 чел. 23-52 года); 2) будущие сотрудники полиции - курсанты вузов МВД России (164 чел. 18-22 года); 3) представители гражданских профессий (132 чел. 23-54 года); 4) будущие представители гражданских профессий - студенты гражданских вузов (139 чел. 18-22 года). В выборке, таким образом, обнаруживается внутреннее деление по возрастному (студенты и курсанты, с одной стороны, и офицеры полиции и лица гражданских профессий - с другой) и по профессиональному признаку: с одной стороны, лица, имеющие (в настоящем или будущем) отношение к деятельности органов правопорядка и раскрытию преступлений (курсанты и офицеры полиции), и лица (студенты и представители гражданских профессий), чья будущая или настоящая профессиональная деятельность не связана с деятельностью ОВД, - с другой. Исследование проводилось в Приволжском федеральном округе.

Данные опросного исследования и их интерпретащия. Возрастные (но не профессиональные) дифференциации (см. рис. 1) проявились уже в ответах на первый вопрос анкеты. Так, в группах курсантов $(27,90 \%)$ и студентов $(30,80 \%)$ достаточно велико число убежденных в том, что стремление к наживе заложено в природе человека, поэтому только постоянный контроль и жесткая отчетность могут каким-то образом уберечь человека от преступления. В данном случае достаточно сложно сказать, является ли свойственная молодежи убежденность в порочности человеческой натуры и, как следствие, в необходимости жесткого контроля преходящей характеристикой юного возраста, либо это значимая черта современного молодого поколения, которая не исчезнет, когда

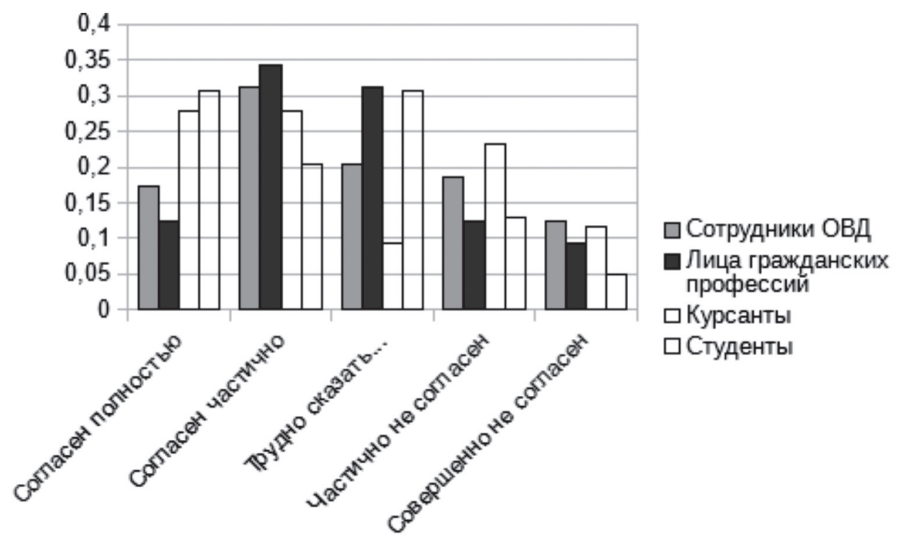

Рисунок 1. Степень согласия респондентов с утверждением: «Стремление к наживе заложено в природе человека. Поэтому только постоянный контроль и жесткая отчетность могут каким-то образом уберечь человека от преступления», \% 
это поколение станет взрослее. Ответ на данный вопрос мы могли бы получить, лишь проведя повторное исследование среди нынешних студентов и курсантов тогда, когда они проработают какое-то время в своей профессии после окончания вуза.

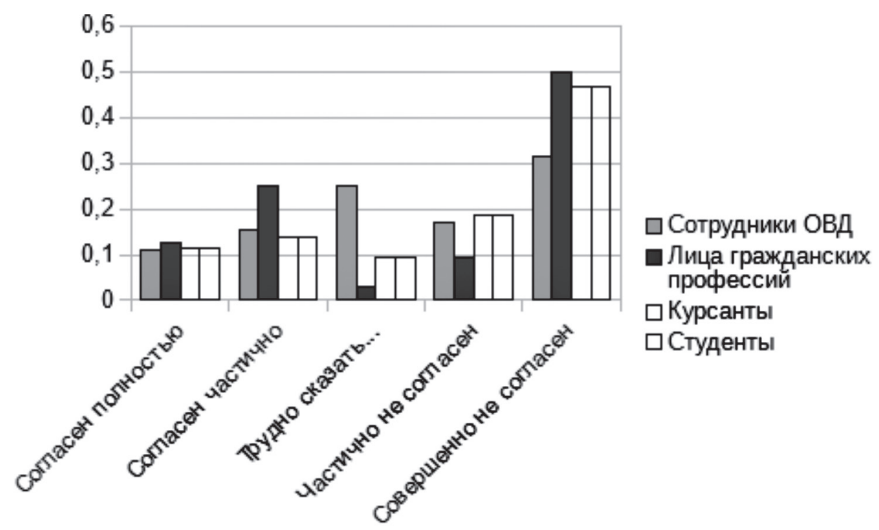

Рисунок 2. Степень согласия респондентов с утверждением: «Чтобы искоренить коррупцию, нужно жестче наказывать преступников-коррупционеров. Коррупционные преступления совершаются, так как возможное наказание слишком мягкое», \%

Существует мнение, что ужесточение наказания за коррупционные преступления - наиболее эффективный способ противодействия коррупции. Диаграмма на рис. 2 наглядно иллюстрирует отношение респондентов к такой позиции. Как мы видим, во всех категориях респондентов большинство полностью либо частично такое мнение разделяют. Между тем число тех, кто безоговорочно принимает такую позицию, в разных выборках неодинаково.

В ведомственной выборке мы видим относительное единодушие: здесь чуть более половины респондентов (54,70\% офицеров полиции и 51,20\% курсантов) убеждены, что именно суровость наказания является главным стимулом не совершать коррупционные преступления. Такие ответы в данном случае вполне закономерны: примерно половина сотрудников правоохранительных органов традиционно склоняются к ужесточению наказания как главному методу борьбы с преступностью, другая половина, признавая значимость наказания, ищет и другие пути противодействия преступным деяниям.

Более всего в эффективности максимально сурового наказания для коррупционеров уверены студенты (69\%). Скорее всего, многие из них на данный момент не думали об иных, помимо наказания, инструментах противодействия преступности.

Люди гражданских профессий с осторожностью выступают за ужесточение наказания за коррупционные деяния: возможно, житейский опыт подсказывает им, что не только или не столько в пенитенциарных мерах заключается решение вопроса.

В данном случае нелишним будет вспомнить, насколько суровыми были наказания за мздоимство на Руси и в Российской империи. Иван Грозный велел четвертовать дьяка, не устоявшего перед взяткой в форме гуся, «фаршированного» серебряными монетами. В середине XVII в. царь Алексей Михайлович отдал на растерзание толпе главу Земского приказа Плещеева и главу Пушкарского при- 
каза Траханиотова (в нынешнем понимании - министра), чье циничное вымогательство спровоцировало народные волнения в Москве. По указанию Петра I был повешен сибирский губернатор М. Гагарин, а его тело в течение 3 лет не предавали земле и демонстрировали в назидание другим чиновникам. Оберфискал А. Нестеров, который в свое время стал разоблачителем графа Гагарина, сам был обвинен во взяточничестве. Его секли кнутом, пытали на дыбе, а раны засыпали солью и жгли огнем. В 1724 г. Нестерова колесовали: сперва раздробили конечности, а затем обезглавили ${ }^{1}$.

Между тем история показывает, что посредством ужесточения наказания коррупция, увы, не была побеждена. Взяточничество распространилось на Руси еще в период зависимости от Золотой Орды - в XIII в. [Мизерий 2001: 182], а начиная с Ивана Грозного приобрело особый размах.

Характеризуя уже Петровскую Русь, В.О. Ключевский писал о «безмерно разросшемся» омуте «повального взяточничества и казнокрадства» [Ключевский 2005: 603]. С.М. Соловьев приводит многочисленные примеры ужесточения наказания за взяточничество в царской России (от жестокой физической расправы до передачи движимого и недвижимого имущества коррумпированного чиновника лицу, заявившему на него) и небезосновательно утверждает, что эти меры не имели эффекта, а мздоимство становилось все более изощренным [Соловьев 1997: 485-486, 496-497, 591].

А.И. Мизерий, автор весьма любопытной статьи «История борьбы с коррупцией в России», показывает, что распространение суровых карательных мер не приводило к сокращению коррупционных преступлений в царской России. Поэтому уже середине XIX в. русские правоведы стали говорить о предупреждении лихоимства, об устранении не только последствий, но и причин распространенности этого явления [Мизерий 2001: 184]. Многие правоведы стали разделять убеждение знаменитого итальянского юриста и гуманиста Чезаре Беккариа, что в противостоянии преступности главное - не суровость наказания, а его неотвратимость [Беккариа 2016].

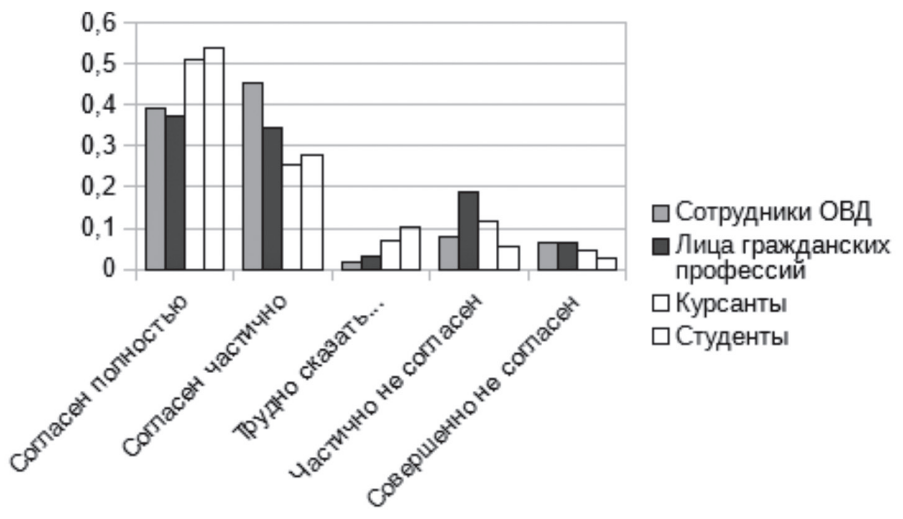

Рисунок 3. Степень согласия респондентов с утверждением: «Главное - не суровость наказания, а его неотвратимость. Нужно стремиться к тому, чтобы все коррупционные преступления раскрывались. Важен сам факт наказания, а не его жестокость», \%

1 Цепляев В. Десять самых суровых наказаний за коррупцию. - Аргументы и факты. № 16. 20.04.2011. 
Слова Ч. Беккариа помогли нам сформулировать третий вопрос (см. рис. 3). Мы увидели, что число людей, которые с мнением великого гуманиста не согласны категорически, невелико. Авторы статьи убеждены, что человек совершает коррупционное деяние не потому, что последующее наказание недостаточно сурово. Он уверен, что факт деяния вообще не будет раскрыт.

Респонденты во всех четырех выборках полностью либо частично разделяют мнение итальянского юриста. При этом в молодежной выборке «градус гуманизма» более высок. Так, среди курсантов $(51,20 \%)$, и студентов $(53,80 \%)$ число полностью разделяющих мнение, что неотвратимость наказания важнее его жестокости, заметно больше, чем среди офицеров полиции $(39,10 \%)$ и лиц гражданских профессий $(37,50 \%)$. Гуманистический настрой молодежного сегмента мы оцениваем как позитивный знак.

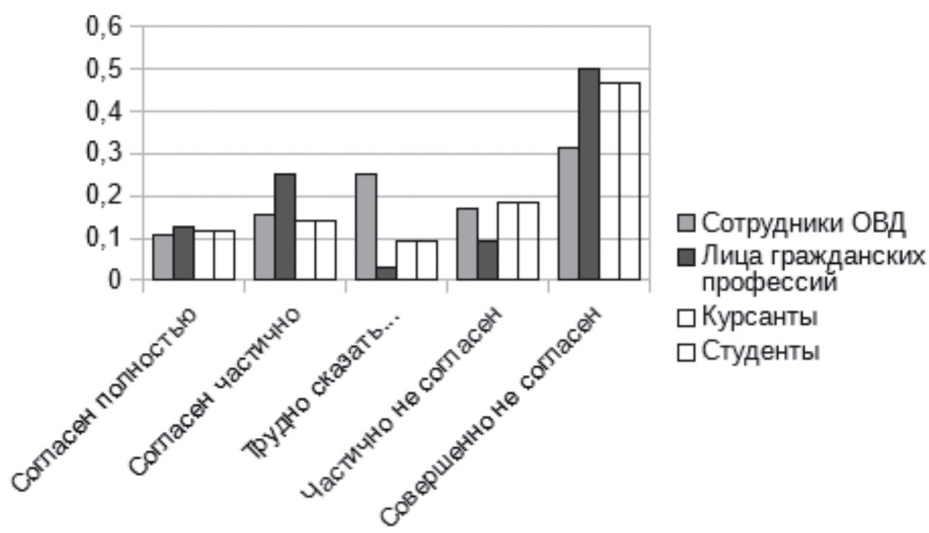

Рисунок 4. Степень согласия респондентов с утверждением: «Бороться с коррупцией бессмысленно. Она была, есть и будет. А ее формы становятся более изощренными», \%

Последний вопрос имел целью понять уровень пессимизма различных опрашиваемых аудиторий в отношении разного рода усилий, направленных на борьбу с коррупцией (см. рис. 4). В данном случае наибольшими пессимистами оказались люди гражданских профессий. Возможно, печальный опыт некоторых из них заставляет частично $(25 \%)$ или полностью $(12,5 \%)$ соглашаться с тем, что бороться с коррупцией не имеет смысла. Однако именно среди людей гражданских профессий больше всего и тех, кто категорически не согласен с тем, что бороться с коррупцией бессмысленно - 50\%. Такого же мнения придерживаются многие курсанты $(46,50 \%)$ и студенты (также 46,50\%) и только $31,30 \%$ сотрудников ОВД. Среди офицеров полиции также более всего тех, кому «трудно сказать» - 25\%. Такие ответы, безусловно, связаны с тем, что бороться с коррупцией действительно нелегко, и сотрудники органов внутренних дел знают это из собственного опыта.

Но даже если предположить, что вряд ли когда-нибудь удастся полностью искоренить коррупцию, это вовсе не означает, что борьба с ней бессмысленна. В разные эпохи и в разных обществах бывали периоды «коррупционного пика» и периоды снижения уровня коррупционной преступности.

Заключение. Материалы проведенного исследования показывают, что вопросы осмысления коррупции как социального явления волнуют представителей различных групп российского общества. В разных общественных группах люди достаточно взвешенно относятся к тому, как именно следует противодей- 
ствовать коррупции: через суровость наказания или посредством его неотвратимости. В каждом сегменте выборки немалое число опрашиваемых склоняется к тому, что эффективность противодействия коррупции - в ужесточении наказания за коррупционные деяния. Немало и тех, кто делает ставку на неотвратимость наказания, а не на его суровость. Мы также могли убедиться, что среди молодежи (студенты и курсанты) больше тех, кто возлагает надежды на неизбежность наказания, а не на его жестокость.

В целом, люди смотрят на будущее с оптимизмом и вовсе не склонны считать борьбу с коррупцией бесполезным делом. При этом сотрудники правоохранительных органов глубже осознают сложность противостояния коррупции.

Активное взаимодействие институтов государственной власти, правоохранительных органов и гражданского общества способно дать продуктивный эффект в борьбе с коррупцией, основанной в первую очередь на профилактической работе.

Именно для профилактики коррупционного поведения в обществе будет в первую очередь полезна наша исследовательская работа. Эмпирически добытое знание об отношении общества к проблеме коррупции, в особенности его профессиональных и возрастных групп, - это именно то, что необходимо органам правопорядка для организации грамотной профилактической антикоррупционной работы.

\section{Список литературы}

Баумик С.К. 2015. Сложность контроля над коррупцией в условиях политической демократии. - Актуальные проблемы экономики и права. № 4(36). C. 26-35.

Беккариа Ч. 2016. О преступлениях и наказаниях. М.: НИЦ ИНФРА-М. 184 с. Добросоцкий В.И. 2016. Противодействие коррупции: научные подходы и практические инструменты. - Право и управление. ХХІ век. № 2(39). С. 120-124.

Ключевский В.О. 2005. Русская история: полный курс лекций. М.: ОлмаПресс Образование. 832 с.

Мизерий А.И. 2001. История борьбы с коррупцией в России. - Вестник Нижегородского университета им. Н.И. Лобачевского. № 2. С. 182-189.

Савченко И.А. 2019. Коррупционное поведение в категориях философии права. - Конституция Российской Федерации и современный правопорядок: материалы конференции. В 5 ч. Ч. 1. С. 391-393.

Савченко И.А., Снегирева Л.А., Устинкин С.В. 2018. Причины коррупции в кросс-методологическом измерении. - Власть. Т. 26. № 5. С. 146-149.

Савченко И.А., Снегирева Л.А., Устинкин С.В. 2019а. Коррупционная личность в восприятии профессиональных и возрастных социальных групп. Власть. Т. 27. № 3. С. 135-144.

Савченко И.А., Снегирева Л.А., Устинкин С.В. 2019б. Истоки коррупции в эмпирическом измерении. - Вестник Нижегородской академии МВД России. № 2(46). С. 157-163.

Соловьев С.М. 1997. История России с древнейших времен. М.: Голос; КолоколПресс. Т. 14. Кн. 7. 812 c.

Davis Ja.H., Ruhe J.A. 2003. Perceptions of Country Corruption: Antecedents and Outcomes. - Journal of Business Ethics. Vol. 43. Is. 4. P. 275-288.

Gokcekus O., Bengyak K. 2014. Peculiar Dynamics of Corruption: Religion, Gender, EU Membership, and Others. World Scientific Publishing Co. 155 p.

Nielsen R.P. 2003. Corruption Networks and Implications for Ethical Corruption Reform. - Journal of Business Ethics. Vol. 42. Is. 2. P. 125-149.

Wilhelm P.G. 2002. International Validation of the Corruption Perceptions Index: 
Implications for Business Ethics and Entrepreneurship Education. - Journal of Business Ethics. Vol. 35. Is. 3. P. 177-189.

SAVCHENKO Irina Aleksandrovna, Dr.Sci. (Soc.), Professor of the Chair of Philosophy, Sociology and Theory of Social Communication, Dobroljubov State Linguistics University of Nizhny Novgorod (31a Minina St, Nizhny Novgorod, Russia, 603155); Professor of the Chair of Philosophy, Nizhny Novgorod Academy of Ministry of Internal Affairs of the Russian Federation (3 Ankudinovskoye Highway, Nizhny Novgorod, Russia, 603144; teosmaco@rambler.ru)

SNEGIREVA Lyudmila Anatol'evna, Cand.Sci. (Psych.), Associate Professor; Chief of the Chair of Philosophy, Nizhny Novgorod Academy of Ministry of Internal Affairs of the Russian Federation (3 Ankudinovskoye Highway, Nizhny Novgorod, Russia, 603144; sla_sq@mail.ru)

USTINKIN Sergei Vasil'evich, Dr.Sci. (Hist.), Professor; Dean of Faculty of International Relations, Economics and Management, Professor of the Chair of International Relations and Political Science, Dobroljubov State Linguistics University of Nizhny Novgorod (31a Minina St, Nizhny Novgorod, Russia, 603155); Director of Volga branch of the Federal Center of Theoretical and Applied Sociology, Russian Academy of Sciences (4 Holodny Lane, Nizhny Novgorod, Russia, 603000; sv.ustinkin@gmail.com)

\section{BETWEEN SEVERITY AND INEVITABILITY: ANTI-CORRUPTION IN UNDERSTANDING OF VARIOUS POPULATION GROUPS}

\footnotetext{
Abstract. Corruption is one of "big calls" for international community. Therefore, creation of society without corruption is objectively a priority reference point of social development in many countries. It is not absolutely clear in what case fight against corruption will be most effective. At strict control and toughening of punishment for corruption acts, or, perhaps, when ensuring inevitability of punishment? In this case, most likely, has the rigidity of punishment secondary importance? Whether it possible to win against corruption in general? Similar questions objectively arise not only before scientists, but also before representatives of various groups of public.

To receive answers to the matters from representatives of various groups of population, the authors conducted a polling research among police officers, cadets of higher education institutions of the Ministry of Internal Affairs, representatives of civilian professions and students of civil higher education institutions.

The purpose of the research is to establish the opinion of different social groups to conceptual installations on which the anticorruption system could be formed. The authors sought to find out first of all opinions of respondents on the most effective anti-corruption method: severity of punishment or its inevitability.

In general, people look to the future with optimism and are not inclined to consider fight against corruption as useless business. At the same time, law enforcement officers realize complexity of opposition to corruption more deeply.

Keywords: anti-corruption, bribery, severity, inevitability, police, internal affairs officers
} 